\title{
Separation and Selective Formation of Fullerene Adducts within an $\mathrm{M}_{8}{ }_{8} \mathrm{~L}_{6}$ Cage
}

\author{
Wolfgang Brenner, Tanya K. Ronson, and Jonathan R. Nitschke*(i) \\ Department of Chemistry, University of Cambridge, Lensfield Road, Cambridge CB2 1EW, United Kingdom
}

Supporting Information

ABSTRACT: The self-assembly of 4-fold-symmetric porphyrins with $\mathrm{Fe}^{\mathrm{II}}$ or $\mathrm{Zn}^{\mathrm{II}}$ gave a new cubic $\mathrm{M}_{8}^{\mathrm{II}} \mathrm{L}_{6}$ cage framework with electron-deficient walls. This cage bound $\mathrm{C}_{60}$-indene or $\mathrm{C}_{60}$-anthracene bisadducts selectively, whereas unfunctionalized fullerenes and monoadducts were not encapsulated. The $\mathrm{Fe}^{\mathrm{II}}{ }_{8} \mathrm{~L}_{6}$ cage also enabled the reaction of $\mathrm{C}_{60}$ and anthracene to yield the bisadducts selectively under conditions where no reaction was observed in the absence of the cage. These findings have relevance in the context of polymer solar cells, where $\mathrm{C}_{60}$ bisadducts have found use as electron acceptors, because these adducts currently require laborious and timeconsuming syntheses and purification.

$\mathrm{C}$ ontainer molecules offering well-defined inner voids have garnered much interest in recent years, ${ }^{1}$ especially in the context of functions such as substrate stabilization ${ }^{2}$ and catalytic transformations of specific substrates. ${ }^{3}$ In many cases, the size of an optimal guest can be estimated with the help of Rebek's 55\% rule. ${ }^{4}$ As noted by the progenitors of this rule, the use of larger capsules and systems resembling natural binding pockets might be expected to result in deviation from the $55 \%$ optimum. Such larger capsules are attractive because they would enable, as in nature, selective reactions on large biomolecules, such as proteins, and provide a platform to bind large guests selectively, such as fullerenes.

Since their discovery in $1985,{ }^{5}$ fullerenes have impacted fields that include biomedical chemistry, ${ }^{6}$ materials science, ${ }^{7}$ and solar energy conversion. ${ }^{8}$ Several synthetic routes concerning their functionalization have been established, such as the Bingel reaction, ${ }^{9}$ the Prato reaction, ${ }^{10}$ and different Diels-Alder reactions. ${ }^{11}$ The spherical nature of fullerenes and the presence of multiple reactive bonds, however, make it difficult to selectively synthesize fullerenes bearing a defined number of functional groups. Thus, purification of substituted fullerenes usually involves tedious separation of the desired fullerenes by column chromatography or by HPLC. The Diederich ${ }^{12}$ and Hirsch ${ }^{13}$ groups, among others, have developed methods for the selective generation of multiply substituted fullerenes, for example, via tether-directed remote functionalization. ${ }^{12}$ As preparing and installing the tether is a synthetically costly process, we aimed to generate a molecular cage that would allow the separation of the desired fullerenes and possibly even control the reactivity of fullerenes.

The present study has the goal of generating larger cages in order selectively to encapsulate functionalized fullerenes, based upon past development of molecular containers for $\mathrm{C}_{60}$ and $\mathrm{C}_{70} \cdot{ }^{14} \mathrm{We}$ focus upon Diels-Alder functionalized fullerenes and aim at the selective formation and separation of bisadducts within the inner void of molecular cages. Such bisadducts have found uses. For example, bis-indene functionalized $\mathrm{C}_{60}\left(\mathrm{C}_{60} \mathrm{Ind}_{2}\right)^{15}$ is one of the most promising electron-acceptors for increasing the power conversion efficiency (PCE) of fullerene-based polymer solar cells.

Following the Fujita group's insight that electron-poor host frameworks tend to bind even electron-poor guests with the highest affinity and selectivity, ${ }^{16}$ we hypothesized that the incorporation of electron-poor perfluorophenylene groups into a cage framework might optimize fullerene binding. Multiply fluorinated anilines are too electron-poor to condense into hydrolytically stable imines on metal templates, ${ }^{17}$ however, leading us to consider use of the triazolyl-pyridine coordination motif that had been successfully employed by Lusby ${ }^{18}$ and $\mathrm{Heitz}^{19}$ to generate elegant three-dimensional architectures. Ligand $\mathbf{L}$ (see Figure 1) was thus designed to generate the electron-deficient cubic framework of $\mathrm{Fe}^{\mathrm{II}}{ }_{8} \mathrm{~L}_{6}$ cage 1 consisting of a tetrakis(perfluorophenylene)nickel-porphyrin core bearing four triazolyl-pyridine chelating groups.

L was prepared from nickel-5,10,15,20-tetrakis(pentafluorophenyl)porphyrin in two steps, as shown in Figure S3. ${ }^{20}$ The reaction of $\mathbf{L}$ (6 equiv) with iron(II) triflimide (8 equiv) in acetonitrile at $70{ }^{\circ} \mathrm{C}$ resulted in the formation of cubic $\mathrm{Fe}^{\mathrm{II}}{ }_{8} \mathrm{~L}_{6}$ cage 1 (see Figure 1). Carrying out the same reaction with zinc(II) triflimide instead of iron(II) triflimide yielded the corresponding cubic $\mathrm{Zn}_{8}{ }_{8} \mathrm{~L}_{6}$ cage 2 , indicating that the formation of a cubic $\mathrm{M}^{\mathrm{II}}{ }_{8} \mathrm{~L}_{6}$ framework is a general feature of this ligand and is not restricted to a specific metal.

Single-crystal X-ray diffraction analysis ${ }^{21}$ (see Figure 1) confirmed the approximately $O$-symmetric structure of $\mathbf{1}$ in the solid state. The eight tris(pyridylimine) $\mathrm{Fe}^{\mathrm{II}}$ vertices in each cage display facial coordination and share the same $\Delta$ or $\Lambda$ stereochemistry; both enantiomers are present in the crystal lattice. Each face of the assembly consists of a Ni-porphyrin-based ligand, which adopts a planar conformation. The average $\mathrm{Ni}-\mathrm{Ni}$ distance between opposite faces is $19.5 \AA$, and the inner void volume was $3183 \AA^{3}$ (see Figure S52). The largest sphere that could enter or exit the cavity through a pore without distorting the host framework would have a diameter of $4.3 \AA$.

Guest encapsulation within $\mathbf{1}$ was probed using ${ }^{19} \mathrm{~F}$ NMR spectroscopy, whereby the chemical shifts of the inward-facing fluorine atoms were observed to act as sensitive probes of their

Received: November 6, 2016

Published: December 20, 2016 

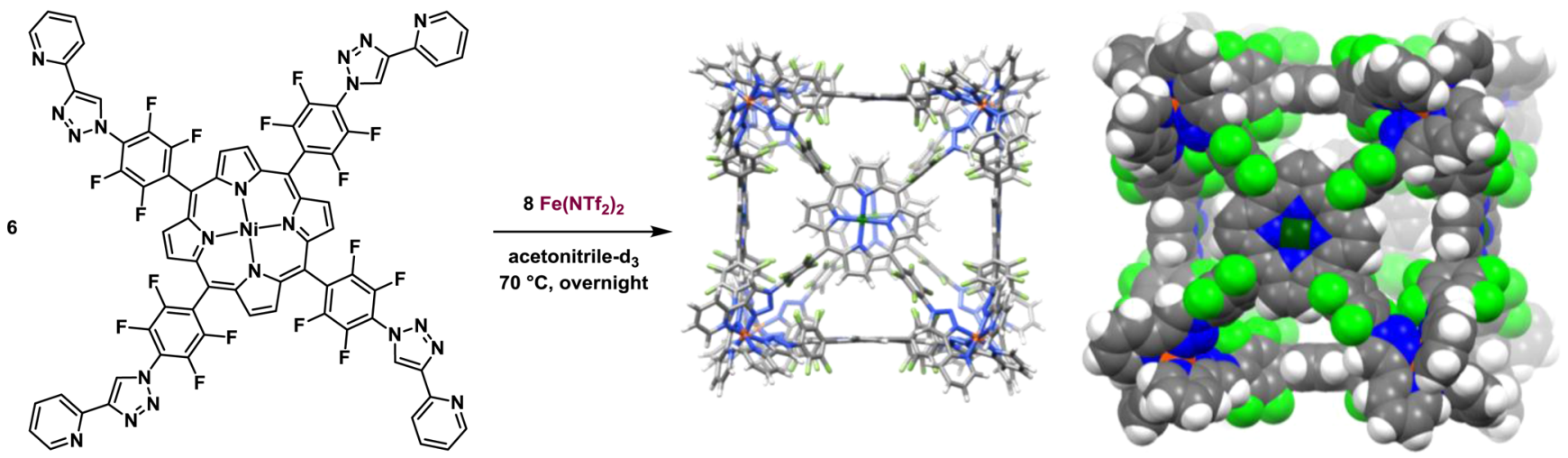

Figure 1. Formation of $\mathbf{1}$ based on the self-assembly of ligand $\mathbf{L}$ and iron(II) triflimide. The crystal structure of $\mathbf{1}$ is depicted at right in two different styles with the space-filling view illustrating the relatively large pores (Fe, orange; $\mathrm{Ni}$, dark green; $\mathrm{N}$, blue; $\mathrm{F}$, pale green; $\mathrm{C}$, gray; $\mathrm{H}$, white). Counteranions and disorder are omitted for clarity.

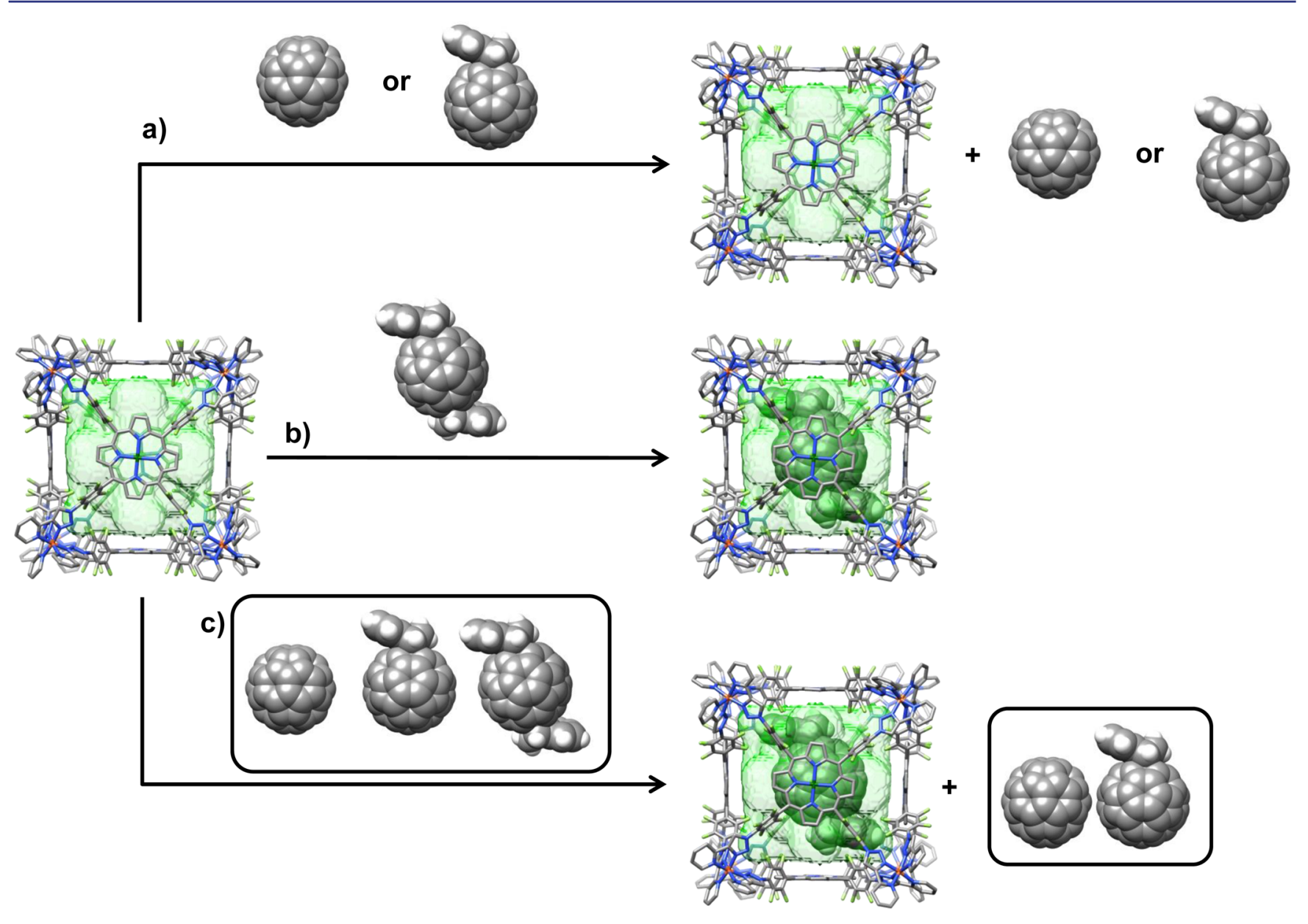

Figure 2. Host-guest chemistry of cubic cage 1: (a) treatment with pure fullerene $\mathrm{C}_{60}$ or $\mathrm{C}_{60} \mathrm{Ind}_{1}$ did not lead to the formation of host-guest complexes; (b) treatment with bisadducts $\mathrm{C}_{60} \operatorname{Ind}_{2}$ yields $\mathrm{C}_{60} \operatorname{Ind}_{2} \subset \mathbf{1}$; (c) treatment of the cage with an unpurified sample containing the reaction mixture between $\mathrm{C}_{60}$ and indene leads to the selective encapsulation of bisadducts within the cage. Only one positional isomer of the bisadducts is shown for clarity.

chemical environments; ${ }^{22}{ }^{19} \mathrm{~F}$ NOESY and COSY experiments confirmed that the structure adopted by $\mathbf{1}$ in the crystal was maintained in solution (see ESI section 4.1); many (>100) attempts to obtain X-ray quality crystals of the host-guest complex were unsuccessful.

Although some large container molecules are able to encapsulate relatively small molecules due to favorable Coulombic interactions, ${ }^{23}$ no evidence was observed for the encapsulation by 1 of the large anions $\mathrm{Mo}_{6} \mathrm{O}_{19}{ }^{2-}, \mathrm{B}_{12} \mathrm{~F}_{12}{ }^{2-}, \mathrm{BPh}_{4}{ }^{-}$,
$\mathrm{CB}_{11} \mathrm{H}_{12}{ }^{-}$, or $\mathrm{B}\left(\mathrm{C}_{6} \mathrm{~F}_{5}\right)_{4}{ }^{-}$(see ESI section 6.1). Cage 1 was also not observed to encapsulate $\mathrm{C}_{60}, \mathrm{C}_{70}$, or any of the higher fullerenes present in fullerene soot (see ESI section 6.2). By Rebek's 55\% rule, ${ }^{4}$ the $3183 \AA^{3}$ inner void of 1 should optimally encapsulate guests having volumes around $1750 \AA^{3}$. We reasoned that, whereas spherical guests such as unsubstituted fullerenes would be expected to favor high occupancy ratios, the functionalization of fullerenes should lead to molecules that, once encapsulated, exhibit stacking interactions with the inside of 

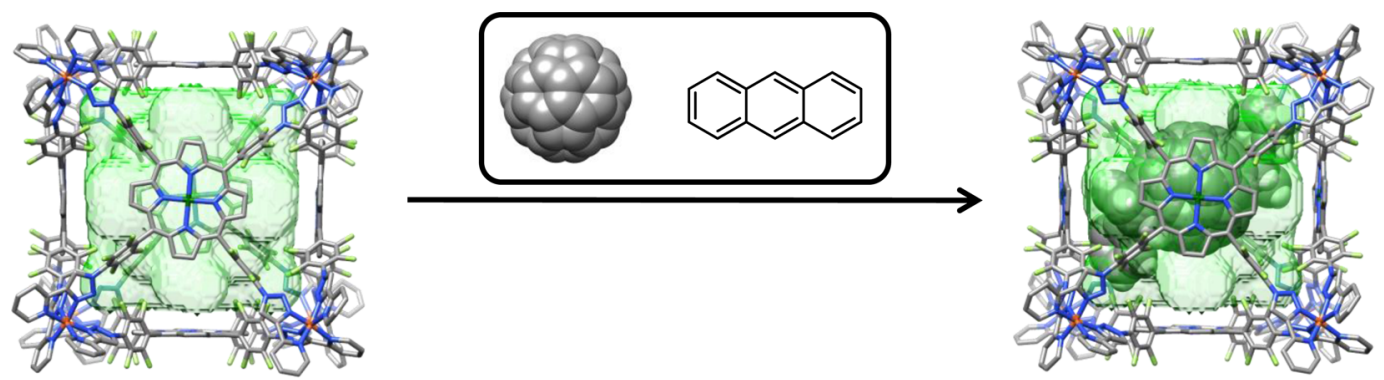

Figure 3. In situ reaction between $\mathrm{C}_{60}$ and anthracene inside $\mathbf{1}$ and preferential formation of $\mathrm{C}_{60} \mathrm{An}_{2} \subset \mathbf{1}$. Only one positional isomer of the bisadducts is shown for clarity.

the cage and are too big to exit via the pores. Our targeted DielsAlder-functionalized fullerenes fulfill these criteria well.

Since Li's initial study of $\mathrm{C}_{60} \mathrm{Ind}_{2},{ }^{15}$ many other, similarly substituted bisadducts have shown remarkable PCEs, ${ }^{24}$ highlighting the value of establishing a method to separate these desired products from their reaction mixtures, a problem that is present, in a general way, across many industries and that accounts for ever-increasing consumption of energy and capital. ${ }^{25}$ Following known procedures, the mono- and bis-indene- $\mathrm{C}_{60}$ adducts were obtained (see Figure S1) and purified by column chromatography. ${ }^{15,26}$ Host-guest studies were carried out by adding an excess of the respective adduct to a solution of $\mathbf{1}$ in deuterated acetonitrile and heating the sample for $16 \mathrm{~h}$ at $70{ }^{\circ} \mathrm{C}$ (Figure 2). In the case of the monoadduct $\mathrm{C}_{60}$ Ind $_{1}$, no evidence for encapsulation was observed by NMR or ESI-MS (see ESI section 6.2). However, addition of the mixture of bis-adducts $\mathrm{C}_{60} \mathrm{Ind}_{2}$ in acetonitrile led to the formation of stable host-guest complexes ( $44 \%$ of 1 with $\mathrm{C}_{60} \mathrm{Ind}_{2}$ inside, compared to $56 \%$ of still empty 1 based on ${ }^{19} \mathrm{~F}$ NMR) with slow guest exchange on the NMR time scale (see ESI section 5.1). The determination of quantitative binding constants was precluded by the incompatible solubilities of 1 and $\mathrm{C}_{60} \operatorname{Ind}_{2}$ (and other fullerene species in general). Although our guest binding studies focused on cage 1 due to its greater ${ }^{19} \mathrm{~F}$ NMR signal dispersion, cage 2 was also shown to bind $\mathrm{C}_{60} \mathrm{Ind}_{2}$ in a representative guest binding test (see ESI section 5.5).

Having shown that from among purified $\mathrm{C}_{60}, \mathrm{C}_{60} \mathrm{Ind}_{1}$, and $\mathrm{C}_{60} \mathrm{Ind}_{2}$, only the largest adduct was encapsulated within the cage, we turned our attention to the reaction mixture. The selective encapsulation of the bisadduct from the reaction mixture is especially appealing as commercially available sources still rely on separation by HPLC. ${ }^{27}$ Therefore, an excess of the crude reaction mixture with no prior purification was added to an acetonitrile solution of 1 . After $19.5 \mathrm{~h}$ at $50^{\circ} \mathrm{C}$, encapsulation only of $\mathrm{C}_{60} \mathrm{Ind}_{2}$ was observed by NMR spectroscopy and mass spectrometry (see Figures S36-S39).

With the successful encapsulation of $\mathrm{C}_{60} \mathrm{Ind}_{2}$ despite its low cavity occupancy (see Table S1), we turned to a different DielsAlder diene, anthracene, to explore whether a general trend was present. The reaction between $\mathrm{C}_{60}$ and anthracene was carried out following the literature procedure, ${ }^{11 a, 28}$ and the different adducts were obtained by preparative thin-layer chromatography (see Figure S2). Host-guest studies with the purified mono- and bis-anthracene- $\mathrm{C}_{60}$ adducts yielded results identical to those obtained with the indene-functionalized fullerenes: specific encapsulation of the bisadducts $\mathrm{C}_{60} \mathrm{An}_{2}$ (30\% of 1 with $\mathrm{C}_{60} \mathrm{An}_{2}$ inside, compared to $70 \%$ of still empty 1 based on ${ }^{19} \mathrm{~F}$ NMR, see Figures S40-S43) and no evidence of interaction with unreacted $\mathrm{C}_{60}$ or the monoadduct (see ESI section 6.2).
In a proof-of-concept study, we sought to demonstrate that cage 1 could be employed to generate selectively bisadducts from among different possible products (Figure 3). Anthracene is more reactive than indene toward $\mathrm{C}_{60}$, with both the Diels-Alder and the retro-Diels-Alder reactions starting to take place at $50{ }^{\circ} \mathrm{C} .{ }^{11 \mathrm{a}} \mathrm{We}$ hypothesized that the Diels-Alder reaction between $\mathrm{C}_{60}$ and anthracene in the presence of 1 might therefore lead to the exclusive formation of the bisadducts. The reactants alone are not able to form any host-guest complex with $\mathbf{1}$; also, a test reaction between $\mathrm{C}_{60}$ and anthracene in acetonitrile without 1 at $50{ }^{\circ} \mathrm{C}$ gave neither an anthracene dimer nor any fullereneanthracene adducts. We attribute these findings to the negligible solubility of $\mathrm{C}_{60}$ in acetonitrile and the low solubility of anthracene in the same solvent. However, when we combined $1, \mathrm{C}_{60}$, and anthracene in acetonitrile and heated the sample to $50{ }^{\circ} \mathrm{C}$ overnight, NMR analysis (see Figures S44-S46) indicated host-guest complex formation. Analysis by mass spectrometry was impeded by the tendency of the guests to undergo retroDiels-Alder fragmentation, as exemplified by the observation of peaks corresponding to $\mathrm{C}_{60} \subset 1$ in the matrix-assisted laser desorption/ionization mass spectrum (Figure S47), even though $\mathrm{C}_{60}$ was not observed to bind within 1 . We infer, thus, that the retro-Diels-Alder reaction took place under the conditions employed to record the mass spectrum. Using electrospray ionization, peaks for the host-guest complexes with $\mathrm{C}_{60} \mathrm{An}_{1}$, $\mathrm{C}_{60} \mathrm{An}_{2}$, and $\mathrm{C}_{60} \mathrm{An}_{3}$ were observed, with signals corresponding to $\mathrm{C}_{60} \mathrm{An}_{2} \subset 1$ being the most intense (see Figure S48). As no evidence was found for the encapsulation of the monoadduct in a separate experiment (see ESI section 6.2) and the trisadduct appears too large to fit into $\mathbf{1}$ (see Figure S53), we infer that the bisadduct was formed, and that weakly associated anthracene, which was present in excess, gave rise to the $\mathrm{C}_{60} \mathrm{An}_{3}$ signal. Cage $\mathbf{1}$ thus appears to enable the Diels-Alder reaction between anthracene and $\mathrm{C}_{60}$ to yield specifically the bisadducts, ${ }^{11 a}$ whereas they would not ordinarily react at all under these conditions. We infer that the inner phase of $\mathbf{1}$ favors the formation of the labile $\mathrm{C}_{60} \mathrm{An}_{2}$ product, ${ }^{29}$ generated in a thermodynamically controlled reaction between $\mathrm{C}_{60}$ and anthracene. ${ }^{30}$

Our new cage framework thus presents a large cavity with electron-deficient walls, which can selectively bind fullerene bisadducts such as $\mathrm{C}_{60} \mathrm{Ind}_{2}$ and $\mathrm{C}_{60} \mathrm{An}_{2}$, which have been investigated as solar cell materials; ${ }^{31}$ such binding might ultimately be developed into a means of purification given the ability of such cages to open and close reversibly. ${ }^{18 a, 32}$ Cage $\mathbf{1}$ also enables reaction between species that individually are too small to form host-guest complexes, but which form products that have a favorable size and shape for encapsulation. ${ }^{33}$ This phenomenon could allow for the selective formation of other fullerene adducts of technological value, among other targets. 


\section{ASSOCIATED CONTENT}

\section{S Supporting Information}

The Supporting Information is available free of charge on the ACS Publications website at DOI: 10.1021/jacs.6b11523.

Data for $\mathrm{C}_{464} \mathrm{H}_{168} \mathrm{~F}_{192} \mathrm{Fe}_{8} \mathrm{~N}_{136} \mathrm{Ni}_{6} \mathrm{O}_{64} \mathrm{~S}_{32}$ (CIF)

Experimental details (PDF)

\section{AUTHOR INFORMATION}

\section{Corresponding Author}

*jrn34@cam.ac.uk

\section{ORCID}

Jonathan R. Nitschke: 0000-0002-4060-5122

\section{Notes}

The authors declare no competing financial interest.

\section{ACKNOWLEDGMENTS}

W. Brenner acknowledges the support of the Leopoldina Fellowship Programme, German National Academy of Sciences Leopoldina (grant LPDS 2014-11). This work was supported by the UK Engineering and Physical Sciences Research Council (EPSRC, EP/M008258/1). We thank the EPSRC Mass Spectrometry Service at Swansea for carrying out the high resolution mass spectrometry and Diamond Light Source (UK) for synchrotron beamtime on I19 (MT11397).

\section{REFERENCES}

(1) (a) Cook, T. R.; Stang, P. J. Chem. Rev. 2015, 115, 7001. (b) Cook, T. R.; Zheng, Y.-R.; Stang, P. J. Chem. Rev. 2013, 113, 734.

(2) Galan, A.; Ballester, P. Chem. Soc. Rev. 2016, 45, 1720.

(3) (a) Zhang, G.; Mastalerz, M. Chem. Soc. Rev. 2014, 43, 1934. (b) Marcos, V.; Stephens, A. J.; Jaramillo-Garcia, J.; Nussbaumer, A. L.; Woltering, S. L.; Valero, A.; Lemonnier, J.-F.; Vitorica-Yrezabal, I. J.; Leigh, D. A. Science 2016, 352, 1555. (c) Han, M.; Luo, Y.; Damaschke, B.; Gómez, L.; Ribas, X.; Jose, A.; Peretzki, P.; Seibt, M.; Clever, G. H. Angew. Chem., Int. Ed. 2016, 55, 445. (d) Wang, W.; Wang, Y.-X.; Yang, H.-B. Chem. Soc. Rev. 2016, 45, 2656. (e) Frischmann, P. D.; Kunz, V.; Würthner, F. Angew. Chem., Int. Ed. 2015, 54, 7285. (f) Gütz, C.; Hovorka, R.; Klein, C.; Jiang, Q.-Q.; Bannwarth, C.; Engeser, M.; Schmuck, C.; Assenmacher, W.; Mader, W.; Topić, F.; Rissanen, K.; Grimme, S.; Lützen, A. Angew. Chem., Int. Ed. 2014, 53, 1693. (g) Rybtchinski, B. ACS Nano 2011, 5, 6791. (h) Chen, T.-H.; Popov, I.; Chuang, Y.-C.; Chen, Y.-S.; Miljanic, O. S. Chem. Commun. 2015, 51, 6340. (i) Kuijpers, P. F.; Otte, M.; Dürr, M.; Ivanović-Burmazović, I.; Reek, J. N. H.; de Bruin, B. ACS Catal. 2016, 6, 3106. (j) Kishi, N.; Akita, M.; Yoshizawa, M. Angew. Chem., Int. Ed. 2014, 53, 3604. (k) Leenders, S. H. A. M.; Gramage-Doria, R.; de Bruin, B.; Reek, J. N. H. Chem. Soc. Rev. 2015, 44, 433. (1) Otte, M. ACS Catal. 2016, 6, 6491.

(4) Mecozzi, S.; Rebek, J. J. Chem.—Eur. J. 1998, 4, 1016.

(5) Kroto, H. W.; Heath, J. R.; O’Brien, S. C.; Curl, R. F.; Smalley, R. E. Nature 1985, 318, 162.

(6) Biju, V. Chem. Soc. Rev. 2014, 43, 744.

(7) (a) Popov, A. A.; Yang, S.; Dunsch, L. Chem. Rev. 2013, 113, 5989. (b) Zhang, R.; Murata, M.; Aharen, T.; Wakamiya, A.; Shimoaka, T.; Hasegawa, T.; Murata, Y. Nat. Chem. 2016, 8, 435.

(8) Brabec, C. J.; Gowrisanker, S.; Halls, J. J. M.; Laird, D.; Jia, S.; Williams, S. P. Adv. Mater. 2010, 22, 3839.

(9) Bingel, C. Chem. Ber. 1993, 126, 1957.

(10) Maggini, M.; Scorrano, G.; Prato, M. J. Am. Chem. Soc. 1993, 115, 9798.

(11) (a) Tsuda, M.; Ishida, T.; Nogami, T.; Kurono, S.; Ohashi, M. J. Chem. Soc., Chem. Commun. 1993, 1296. (b) Wilson, S. R.; Lu, Q. Tetrahedron Lett. 1995, 36, 5707.

(12) Isaacs, L.; Haldimann, R. F.; Diederich, F. Angew. Chem., Int. Ed. Engl. 1994, 33, 2339.
(13) (a) Beuerle, F.; Chronakis, N.; Hirsch, A. Chem. Commun. 2005, 3676. (b) Beuerle, F.; Hirsch, A. Chem. - Eur. J. 2009, 15, 7434.

(14) (a) Meng, W.; Breiner, B.; Rissanen, K.; Thoburn, J. D.; Clegg, J. K.; Nitschke, J. R. Angew. Chem., Int. Ed. 2011, 50, 3479. (b) Wood, D. M.; Meng, W.; Ronson, T. K.; Stefankiewicz, A. R.; Sanders, J. K. M.; Nitschke, J. R. Angew. Chem., Int. Ed. 2015, 54, 3988. (c) Wood, C. S.; Browne, C.; Wood, D. M.; Nitschke, J. R. ACS Cent. Sci. 2015, 1, 504. (d) Ronson, T. K.; League, A. B.; Gagliardi, L.; Cramer, C. J.; Nitschke, J. R. J. Am. Chem. Soc. 2014, 136, 15615.

(15) He, Y.; Chen, H.-Y.; Hou, J.; Li, Y. J. Am. Chem. Soc. 2010, 132, 1377.

(16) Takezawa, H.; Murase, T.; Resnati, G.; Metrangolo, P.; Fujita, M.J. Am. Chem. Soc. 2014, 136, 1786.

(17) Schultz, D.; Nitschke, J. R. J. Am. Chem. Soc. 2006, 128, 9887.

(18) (a) Symmers, P. R.; Burke, M. J.; August, D. P.; Thomson, P. I. T.; Nichol, G. S.; Warren, M. R.; Campbell, C. J.; Lusby, P. J. Chem. Sci. 2015, 6, 756. (b) Burke, M. J.; Nichol, G. S.; Lusby, P. J. J.Am. Chem. Soc. 2016, 138, 9308.

(19) (a) Ballester, P.; Claudel, M.; Durot, S.; Kocher, L.; Schoepff, L.; Heitz, V. Chem. - Eur. J. 2015, 21, 15339. (b) Kocher, L.; Durot, S.; Heitz, V. Chem. Commun. 2015, 51, 13181.

(20) Golf, H. R. A.; Reissig, H.-U.; Wiehe, A. Eur. J. Org. Chem. 2015, $2015,1548$.

(21) CCDC 1485730 contains the supplementary crystallographic data for this paper. These data can be obtained free of charge from The Cambridge Crystallographic Data Center via www.ccdc.cam.ac.uk/ data_request/cif.

(22) (a) Zhao, Y.; Markopoulos, G.; Swager, T. M. J. Am. Chem. Soc. 2014, 136, 10683. (b) Koide, T.; Furukawa, K.; Shinokubo, H.; Shin, J.Y.; Kim, K. S.; Kim, D.; Osuka, A. J. Am. Chem. Soc. 2010, 132, 7246.

(23) Ramsay, W. J.; Szczypiński, F. T.; Weissman, H.; Ronson, T. K.; Smulders, M. M. J.; Rybtchinski, B.; Nitschke, J. R. Angew. Chem., Int. Ed. 2015, 54, 5636.

(24) Li, Y. Chem. - Asian J. 2013, 8, 2316.

(25) (a) Sholl, D. S.; Lively, R. P. Nature 2016, 532, 435. (b) Hasell, T.; Miklitz, M.; Stephenson, A.; Little, M. A.; Chong, S. Y.; Clowes, R.; Chen, L.; Holden, D.; Tribello, G. A.; Jelfs, K. E.; Cooper, A. I. J. Am. Chem. Soc. 2016, 138, 1653. (c) Titirici, M.-M.; White, R. J.; Brun, N.; Budarin, V. L.; Su, D. S.; del Monte, F.; Clark, J. H.; MacLachlan, M. J. Chem. Soc. Rev. 2015, 44, 250. (d) Watt, M. M.; Zakharov, L. N.; Haley, M. M.; Johnson, D. W. Angew. Chem., Int. Ed. 2013, 52, 10275. (e) Moyer, B. A.; Custelcean, R.; Hay, B. P.; Sessler, J. L.; BowmanJames, K.; Day, V. W.; Kang, S.-O. Inorg. Chem. 2013, 52, 3473. (f) Rodriguez-Docampo, Z.; Eugenieva-Ilieva, E.; Reyheller, C.; Belenguer, A. M.; Kubik, S.; Otto, S. Chem. Commun. 2011, 47, 9798. (g) Miller, R. G.; Southon, P. D.; Kepert, C. J.; Brooker, S. Inorg. Chem. 2016, 55, 6195.

(26) Puplovskis, A.; Kacens, J.; Neilands, O. Tetrahedron Lett. 1997, 38, 285.

(27) http://www.sigmaaldrich.com/catalog/product/aldrich/ 753955 ?lang=en\&region=GB, retrieved 12 July 2016.

(28) Duarte-Ruiz, A.; Müller, T.; Wurst, K.; Kräutler, B. Tetrahedron 2001, 57, 3709.

(29) Kräutler, B.; Müller, T.; Duarte-Ruiz, A. Chem. - Eur. J. 2001, 7, 3223.

(30) Leenders, S. H. A. M.; Becker, R.; Kumpulainen, T.; de Bruin, B.; Sawada, T.; Kato, T.; Fujita, M.; Reek, J. N. H. Chem. - Eur. J. 2016, 22, 15468.

(31) (a) Kim, Y.; Cho, C.-H.; Kang, H.; Kim, K.-H.; Park, S.; Kang, T. E.; Park, K.; Kim, B. J. Sol. Energy Mater. Sol. Cells 2015, 141, 87. (b) Han, G. D.; Maurano, A.; Weis, J. G.; Bulović, V.; Swager, T. M. Org. Electron. 2016, 31, 48. (c) Sharma, R.; Lee, H.; Gupta, V.; Kim, H.; Kumar, M.; Sharma, C.; Chand, S.; Yoo, S.; Gupta, D. Org. Electron. 2016, 34, 111. (d) Xiao, Z.; Geng, X.; He, D.; Jia, X.; Ding, L. Energy Environ. Sci. 2016, 9, 2114.

(32) Mal, P.; Schultz, D.; Beyeh, K.; Rissanen, K.; Nitschke, J. R. Angew. Chem., Int. Ed. 2008, 47, 8297.

(33) Heinz, T.; Rudkevich, D. M.; Rebek, J. Nature 1998, 394, 764. 